\title{
The Challenges of Online Learning: An Interview with Natalie Reed
}

Natalie Reed (Corresponding author)

Regents Park Community College, United Kingdom

Email: natalie.reed@regentspark.southampton.sch.uk

Received: $23 / 06 / 2020$

Accepted: 10/08/2020

Published: 01/09/2020

Volume: 1 Issue: 2

How to cite this paper: Reed, N. (2020). The Challenges of Online Learning: An Interview with Natalie Reed. Journal of Critical Studies in Language and Literature, 1(3), 77-80

DOI: https://doi.org/10.46809/jcsll.v1i3.31

Copyright (C 2020 by author(s) and Global Talent Academy Ltd. This work is licensed under the Creative Commons Attribution International License (CC BY 4.0).

http://creativecommons.org/licenses/by/4.0/

\section{(c) (i)}

\begin{abstract}
Although online learning has shown significant growth since last decade, it has never been considered as seriously as during this uncertain period of isolation when the novel coronavirus, also known as COVID-19, has moved rapidly across the world in 2020 and affected the education system worldwide. Thus, it is important to examine advantages and disadvantages of online learning, especially in the current lockdown situation. Some previous studies demonstrated that online learning can offer flexibility for learning in terms of financial positions, learners' availability, easy accessibility, mobility and other factors (Bowers \& Kumar, 2015; Merhi, 2011). As a result, online learning technologies have become more popular in the educational system. Thousands of college students use online platforms and technologies to submit their homework, assignments, and quizzes. In fact, the rapid growth of online learning has enabled learners to access education at any time and from any place (Merhi, 2015).

However, at the same time, there are concerns regarding low rates of student engagement and high erosion rates in online programs and courses. For instance, studies have reported a non-completion rate of $75 \%$ in multiple courses (Jun, 2005; Rochester \& Pradel, 2008). Different factors such as lack of motivation, lack of contextual support strategies, and technological impediments can be considered for the high erosion rates in online learning contexts (Broadbent \& Poon, 2015; Chen \& Jang, 2010; Smith \& Ayers, 2006). Studies have also examined the application of various self-regulated learning approaches in online learning contexts and shown that online programs require learners to demonstrate higher levels of selfregulation, self-motivation, and time commitment in compassion with traditional face-to-face learning (Broadbent \& Poon, 2015; Serwatka, 2003). Besides the self-regulation strategies, contextual support is important in online courses. Online students need a variety of support and interaction from their teachers, tutors and even peers (Chen \& Jang, 2010). Some studies have demonstrated that not being present in the same location at the same time eradicates the chance for immediate social interactions to take place among teachers and students in online learning (Smart \& Cappel, 2006). Thus, learners in online learning environments have negative feelings such as confusion isolation, anxiety, and frustration (Piccoli, Ahmad, \& Ives, 2001). Moreover, some studies have reported that lack of instructor presence could lead to student disengagement. Research have pointed out that students are more likely reluctant to online learning when they perceive a lack of social interactions and instructor presence (Capra, 2011; Trello, 2007).

By the way, online learning is becoming a reality of our education system in a time when the world self-isolates. The UK has not been excluded from this situation and its education process has changed since the spring semester of 2020 . The UK became one of 188 countries having suspended the education process. So, the country has decided to continue the education
\end{abstract}


through the online form of distance learning such as online portals, Google Classroom, and Microsoft Teams or platforms like Zoom, Slack and Google Meet and even intelligent online learning programs like Tassomai, Memrise, and Mathletics. Thus, in order to find some answers to our questions about the challenges and issues of online learning that colleges and students have faced during the current lockdown situation, we conducted an interview with Natalie Reed who is the Assistant Headteacher for Teaching and Learning in Regents Park Community College Southampton, the UK.

Keywords: Covid-19, Isolation, Online Learning, Motivation, Self-Regulation, Interaction

\section{Biographical Note}

Natalie Reed has been a teacher for 21 years and has worked in a range of educational settings including FE colleges and both rural and city secondary schools. Since joining Regents Park 4 years ago her role includes teaching English \& English Literature to KS3 \& 4 students, leading a team of curriculum mentors in her role as Professional Mentor, leading whole staff CPD, leading the school's focus on Cultural Capital, leading curriculum areas MFL \& Creative Arts and leading the school's Teaching \& Learning initiatives \& direction. Her passion for Teaching \& Learning is at the centre of every focus in her role and the inclusive nature of student voice data collection underpins this.

\section{Interview}

JCSLL $^{1}$ : What challenges might colleges and students face by the current immediate online learning programs due to pandemic Covid-19?

$\mathbf{N R}^{2}$ : High levels of deprivation prevent efficient or sufficient internet access and/or access to technology. Low levels of aspiration in some households mean that support with technology including Microsoft Teams/Live lessons may be limited. The challenges students/schools face include students falling behind with basic curriculum components as well as inability to access more challenging areas of the curriculum that may have been provided in face-to-face interactions in class. Also, students are now responsible for managing their own time which they have not had to do before and they are also unaccountable for missing lessons and avoiding work for subjects they either don't like or struggle to access. This may mean that some students have perfected skills in some subjects and neglected to make progress at all in others. Teachers have limited ability to motivate students remotely and whilst we have made regular motivational phone calls to students who are particularly poor at handing in on-line work this has had little impact. Creative subjects (Music/Art) have particularly struggled to engage students due to the fact that our catchment area is particularly deprived and so access to materials for some families is problematic if not impossible. For subjects wherein they have provided on-line auto-answer quizzes (such as maths and Science) they have experienced the highest level of engagement with students and this may be because the requirement to write extended answers/concentrate for sustained periods is removed.

JCSLL: What challenges have you faced personally in your online teaching?

NR: Without personal interaction students are less motivated to complete work, or ask for guidance when they struggle with challenging tasks. Sending electronic documents is problematic as not all students have the same access. Recording lessons is time consuming and we have no idea yet if they have been effective (or even seen!). Trying to design work that will engage and inspire students remotely is very challenging and the marking and feedback process is labour intensive because in order to motivate students to continue submitting work the comments from teachers need to be detailed, bespoke and selfexplanatory. Also - the lack of verbal interaction for the purpose of clarification, assessment and whole-class discussion is removed so students are not developing their oral skills and teachers are reliant on students reading detailed comments regularly.

JCSLL: Levy's (2007) reported that students at lower learning levels of their studies are at a higher risk of dropping out than upper level students. Students who are at an earlier year of their studies are more likely to drop the program. Levy argued that students who are in the early stages of their program could be less ready to cope with the academic challenges. On the other hand, students who are in higher years might be more motivated to complete the course, since they have already spent significant time and efforts on it. What do you think in this regard?

NR: I disagree - from our experience the worst uptake for engagement with on-line learning has been with Year 10. This has been a surprise because we expected that they would feel compelled to engage with their GCSE courses for fear of the impact this situation would have on their eventual grades. We also assumed that as they were (seemingly) more invested in their education because they were in the final years of it before moving to FE they would be keen to avoid falling behind/impacting their final grade negatively. However, the national picture (as discussed at a PiXL conference in June) is that Year 10 appear to be the least engaged across the country. Whereas the best engagement has come from Year 7 who 
enthusiastically engage with work and regularly submit work for feedback and I would suggest that this may be due to higher family engagement/support linked to their younger age. Younger students are more likely to seek support at home and discuss their work/feedback.

JCSLL: How important is the role of students' families in online learning?

NR: Very important - in households where there is limited engagement from parents - lack of support/understanding for online learning students became de-motivated to engage with school very early on. Equally in households where there is little value/appreciation placed in education students are significantly less likely to engage. Our catchment is varied but on average significantly deprived and so we have provided paper work packs for homes where students have no access to the internet or technology but these packs have not been returned (on the whole) for marking and teacher assessment so we have no real gauge for how these students are coping academically. The Government scheme which offered to provide laptops and enabled internet dongles for the most vulnerable students arrived too late and the majority of the laptops (although hand delivered by members of our staff to individual homes) were not here in time for students to engage with on-line learning. Further to this - when a student eventually logs in to their learning platform after many months of work being set each week the impact of seeing all the work that needs to be completed can be overwhelming for some and so they make the choice not to even attempt to catch up.

JCSLL: How do you observe the direct correlation between contextual support by teachers, need satisfaction of students, motivation, and performance in online learning.

NR: Remote learning has taught us that the student/teacher relationship is absolutely pivotal in the success or otherwise of every students' progress. We have managed pastoral care by making weekly telephone calls to every student (including Year 11 until very recently) and we have offered individual meetings in school for every student with the hope that whilst discussing general wellbeing/safeguarding etc. we can also support and motivate students to access on-line learning regularly and to a high standard. In a few cases this has been successful and they have begun to hand work in fairly regularly.

JCSLL: How effective have you found online learning?

NR: For those students who are inclined to introversion this period has been successful. In fact, when the year 10 students came in for IAG 1-1 appointments with their tutors quieter more diligent students verbalised that they would prefer to continue working quietly at home after lockdown ends. For students who need careful behaviour management and pastoral support in order to achieve success it has been ineffective. For those students who have great parental support at home it has been effective but for those who have limited structures already in the home it has been ineffective. I feel that I do not have a firm understanding of y students' progress this year compared to my usual understanding of progress at this point in the academic year in usual circumstances.

JCSLL: Do you have any suggestions for developing and improving the online mode of learning?

NR: Students need training in school for how to access learning platforms/basic IT/how to join live lessons/video calls. It would be beneficial for IT curriculums to include basic training in how to access learning platforms - downloading documents, etc. Students need to regularly use on-line learning platforms for weekly homework task which involves a wholeschool policy change. Parents need to engage with schools who offer support/clinics to teach them how to use on-line learning platforms to support their children.

\section{References}

Bowers, J., \& Kumar, P. (2015). Students' Perceptions of Teaching and Social Presence: A Comparative Analysis of FaceTo-Face And Online Learning Environments. International Journal of Web-Based Learning and Teaching Technologies, 10(1), 27-44. https://doi. org/10.4018/ijwltt.2015010103.

Broadbent, J., \& Poon, W. L. (2015). Self-Regulated Learning Strategies \& Academic Achievement in Online Higher Education Learning Environments: A Systematic Review. The Internet and Higher Education, $27,1-13$. https://doi.org/10.1016/j.iheduc.2015. 04.007.

Capra, T. (2011). Online Education: Promise and Problems. Journal of Online Learning and Teaching, 7(2), 288.

Chen, K.-C., \& Jang, S.-J. (2010). Motivation in Online Learning: Testing a Model of Self-Determination Theory. Computers in Human Behavior, 26(4), 741-752. https://doi. org/10.1016/j.chb.2010.01.011.

Jun, J. (2005). Understanding e-dropout? International Journal on E-Learning, 4(2), 229-240

Levy, Y. (2007). Comparing Dropouts And Persistence In E-Learning Courses. Computers \& Education, 48, $185-204$. Retrieved from http://www.qou.edu/arabic/researchProgram/eLearningResearchs/eLDropout.pdf 
Merhi, M.I. (2011). What motivates students to use Podcasting? 17th Americas Conference on Information Systems, Detroit, Michigan, USA, August 4-8

Merhi, M.I. (2015). Factors Influencing Higher Education Students to Adopt Podcast: An Empirical Study. Computers \& Education, 83, pp.32-43

Piccoli, G., Ahmad, R., \& Ives, B. (2001). Web-Based Virtual Learning Environments: A Research Framework and a Preliminary Assessment of Effectiveness in Basic It Skills Training. MIS Quarterly, 25(4), 401-426. https://doi.org/10.2307/3250989

Rochester, C. D., \& Pradel, F. (2008). Students' Perceptions and Satisfaction with a Webbased Human Nutrition Course. American Journal of Pharmaceutical Education, 72(4), 91. https://doi.org/10.5688/aj720491.

Smith, D., \& Ayers, D. (2006). Culturally Responsive Pedagogy and Online Learning: Implications for the Globalized Community College. Community College Journal of Research and Practice, 30, 401-415. doi:10.1080/10668920500442125

Serwatka, J. A. (2003). Assessment in On-Line CIS Courses. Journal of Computer Information Systems, 44(1), 16-20. https://doi.org/10.1080/08874417.2003.11647547.

Smart, K. L., \& Cappel, J. J. (2006). Students' Perceptions of Online Learning: A Comparative Study. Journal of Information Technology Education: Research, 5, 201-219.

Trello, S. (2007). An Analysis of Student Persistence in Online Education. International Journal of Information and Communication Technology Education, 3(3), 47-62. https:// doi.org/10.4018/jicte.2007070105.

\section{Endnotes}

\footnotetext{
${ }^{1}$ Journal of Critical Studies in Language and Literature

${ }^{2}$ Natalie Reed
} 